\title{
Effect of viewing high luminance gratings on the amblyopic visual system
}

\author{
RICHARD SREBRO \\ From the Departments of Ophthalmology and Physiology, University of Texas Health Science Center, \\ Dallas, Texas 75235, USA
}

SUMMARY Five amblyopes viewed high contrast square wave gratings of 8 different spatial frequencies all presented at very high luminance. They were required to indicate the orientation of the grating, horizontal or vertical, and received immediate auditory feedback if incorrect. Each amblyope viewed 480 grating presentations daily for 15 days over 3 weeks. After this 'treatment' improvements in visual acuity and/or visually evoked potentials were observed and persisted after treatment.

Patching the nonamblyopic eye, the only reliable treatment now available for amblyopia, is effective only in young children. Patching does not increase information transfer in the amblyopic eye directly. In an ideal visual system, that is, one in which performance is limited by quantum fluctuations, resolution (at a fixed contrast) improves as the square root of the total quantum flux. ${ }^{1}$ That the visual acuity of normal observers reaches its best level at relatively low photopic luminance may reflect optical limitations (optical aberrations and diffraction). But in the amblyopic eye the best acuity appears also to be attained at low photopic luminance. This acuity is often much poorer than normal and not limited by the eye's optics. Previous studies concerning the effect of luminance on visual performance in amblyopia ${ }^{2-7}$ have been restricted, to luminances below 200 footlamberts $\left(685 \mathrm{~cd} / \mathrm{m}^{2}\right)$. Unpublished evidence has recently been obtained suggesting that the visual acuity of some amblyopic eyes improves at higher luminances $(1000$ to 10000 foot-lamberts $=3426$ to $34260 \mathrm{~cd} / \mathrm{m}^{2}$ ), and therefore it seemed plausible that exposure of the amblyopic eye to patterned targets of high luminance might result in some measurable improvement in the performance of the amblyopic visual system. The results reported here suggest that this presumption might be correct.

\section{Subjects and methods}

Square wave gratings of high contrast seen as disc shaped targets $3.4^{\circ}$ in diameter were presented to the Correspondence to Dr Srcbro. amblyopic eye by a Maxwellian view optical system based on a heat filtered tungsten source. Eight different grating targets of spatial frequencies $2 \cdot 3,3 \cdot 7$, $5 \cdot 5,9 \cdot 2,12 \cdot 0,16 \cdot 6,41 \cdot 4$, and $82 \cdot 8$ cycles per degree were used. At each presentation the orientation (vertical or horizontal) was randomly selected. The luminance of each grating target was approximately 10000 foot-lamberts $\left(34260 \mathrm{~cd} / \mathrm{m}^{2}\right)$. Gratings were presented in randomised blocks of 8 containing all possible spatial frequencies. At each presentation the subject was required to signal the orientation, and auditory feedback was immediately given if the subject's response was incorrect. An experimental session consisted of 480 such presentations and lasted 1 to $1 \frac{1}{4}$ hours. The subjects used their best refractive correction and a natural pupil and sat for 15 sessions on consecutive weekdays (treatment).

Before treatment began each subject was evaluated by an eye examination and by pattern reversal visually evoked potentials (VEPs, see caption of Fig. 1 for details). These were repeated within 3 days after treatment and again after approximately 3 weeks. Visual acuity was measured daily with single Landolt $\mathrm{C}$ targets presented on a computer controlled video display as high contrast black targets on an 11 footlamberts $\left(38 \mathrm{~cd} / \mathrm{m}^{2}\right)$ uniform white background. At each Landolt $C$ target presentation the subject was required to signal the position of the gap, for example, up, down, left, or right. A descending staircase algorythm was used to measure the gap size corresponding to the $50 \%$ correct response level. Twentyfour gap sizes ranging from approximately 1 to 34 minutes of arc were used. The subjects viewed 
Table 1 Effect of treatment

\begin{tabular}{|c|c|c|c|c|c|c|c|c|}
\hline \multirow[t]{2}{*}{ Subject } & \multirow[t]{2}{*}{$\begin{array}{l}\text { Type of } \\
\text { amblyopia }\end{array}$} & \multirow[t]{2}{*}{ Fixation $\ddagger$} & \multicolumn{2}{|c|}{$\begin{array}{l}\text { Line Snellen } \\
\text { visual acuity }\end{array}$} & \multicolumn{2}{|c|}{$\begin{array}{l}\text { Landolt-C } C^{*} \\
\text { visual acuity }\end{array}$} & \multicolumn{2}{|c|}{$\begin{array}{l}V E P \text { amplitude } \dagger \\
\text { ratio }\end{array}$} \\
\hline & & & Beforc & After & Beforc & After & Before & After \\
\hline 164 & Strabismic & Central & $20 / 200$ & $20 / 200$ & $20 / 60$ & $20 / 44$ & $<0 \cdot 10$ & 0.55 \\
\hline 194 & Strabismic & Central & $20 / 200$ & $20 / 200$ & $20 / 120$ & $20 / 48$ & $0 \cdot 14$ & $0 \cdot 25$ \\
\hline 33 & Anisometropic & Eccentric & $20 / 200$ & $20 / 60$ & $20 / 60$ & $20 / 40$ & 0.93 & 0.93 \\
\hline 141 & Strabismic & Eccentric & $20 / 400$ & $20 / 400$ & $20 / 150$ & $20 / 78$ & 0.55 & 0.49 \\
\hline 116 & Strabismic & Eccentric & $20 / 300$ & $20 / 300$ & $20 / 60$ & $20 / 60$ & 0.44 & 0.48 \\
\hline
\end{tabular}

* Single optotypes, $50 \%$ correct response criterion.

+Amplitude of VEP of amblyopic cyc divided by that of nonamblyopic cyc tested in same session using 40 arc minute check size stimulus VEP amplitude measure at peak ncar $100 \mathrm{~ms}$ to trough ncar $140 \mathrm{~ms}$.

$\ddagger$ Visuscopy, parafoveal fixation in the cccentric fixators

the video screen using their amblyopic eyes with their best refractive corrections at a distance of 2 metres.

Five amblyopic subjects served as subjects. They were all adults of 25 to 46 years old and gave their informed consent after a full explanation of the nature of the experiment had been presented to them. Table 1 lists the relevant clinical findings. Subjects 164,194 , and 33 received treatment as children, but no improvement in their amblyopia resulted. Subjects 141 and 116 had never received treatment before.

Because of the high luminance of the stimuli retinal irradiance (watts $/ \mathrm{cm}^{2}$ at the retina) was estimated from measurements of irradiance at the plane of the subject's pupil and compared with safety standards established by the American National Standards Institute (ANSI). ${ }^{\times}$The cornea-retina transmission fraction was taken at one and the pupil size was assumed to be $7 \mathrm{~mm}$ assumptions which ensure a substantial overestimation of retinal irradiance. Irradiance at the plane of the pupil was measured with a radiometer (calibration traceable to the National Bureau of Standards) in 20 nanometer ( $\mathrm{nm}$ ) steps between 200 and $800 \mathrm{~nm}$. No appreciable ultraviolet radiation was measured. Thus the spectral regions of concern are the visible (400 to $700 \mathrm{~nm}$ ) and the near infrared (700 to $1400 \mathrm{~nm})$, the so called 'retinal hazard region'.' In the visible the retinal irradiance was 1.64 milliwatts $/ \mathrm{cm}^{2}$, which is lower than the ANSI maximum permissible exposure (MPE) for prolonged viewing, for example, 3.1 milliwatts $/ \mathrm{cm}^{2}$. It was not possible to measure the radiation in the near infrared because the sensitivity of the radiometer was too low. Instead it was calculated from the measurements in the visible using the black body equation. This overestimates the radiation exposure because the effect of the heat filter is neglected. In the near infrared the retinal irradiance was 11.8 milliwatts $/ \mathrm{cm}^{2}$, which is lower than the MPE for prolonged viewing, for example, 304.8 milliwatts $/ \mathrm{cm}^{2}$.

\section{Results}

Table 1 shows the visual acuities before and immediately after treatment. Line Snellen acuity was improved for only one subject (33) from 20/200 before treatment to $20 / 60$ after treatment. However, Landolt-C single optotype visual acuity was improved for 4 of the 5 subjects.

Fig. 1 shows VEPs before and immediately after treatment for one subject (164). The pretreatment VEPs were very poor, and no reliable VEP at all could be recorded by the 40 arc minute check size stimulus. After treatment the VEPs of the amblyopic eye were substantially larger, and a definite VEP was recorded by the 40 arc minute check size stimulus.

Table 1 lists the VEP results for all 5 subjects as the ratio of VEP amplitude (amblyopic eye/nonamblyopic eye, 40 arc minute checkerboard, both VEPs recorded in one session). The VEPs from the amblyopic eyes of 2 subjects (164 and 194) were substantially larger after treatment than before. There was essentially no change in the VEP amplitudes for the other 3 subjects.

The following reports were volunteered by the subjects during the course of treatment. Subject 116 reported monocular diplopia at the end of the second week of treatment. Subjects 164 and 33 reported improvements in the ability to carry out simple visually guided motor tasks using only the amblyopic eye. Subjects 33 and 116 reported improved visual recognition of objects. Subjects 164, 194, and 141 reported photopsias, described as punctate and generally colourless, observable only in a dark room, and not localised to any specific part of the visual field.

Follow up examinations at approximately 3 weeks after treatment confirmed the results shown in Fig. 1 and Table 1. In particular, subjects 164 and 194 maintained their increases in VEP amplitude 3 weeks after treatment, but there was no improvement in line 

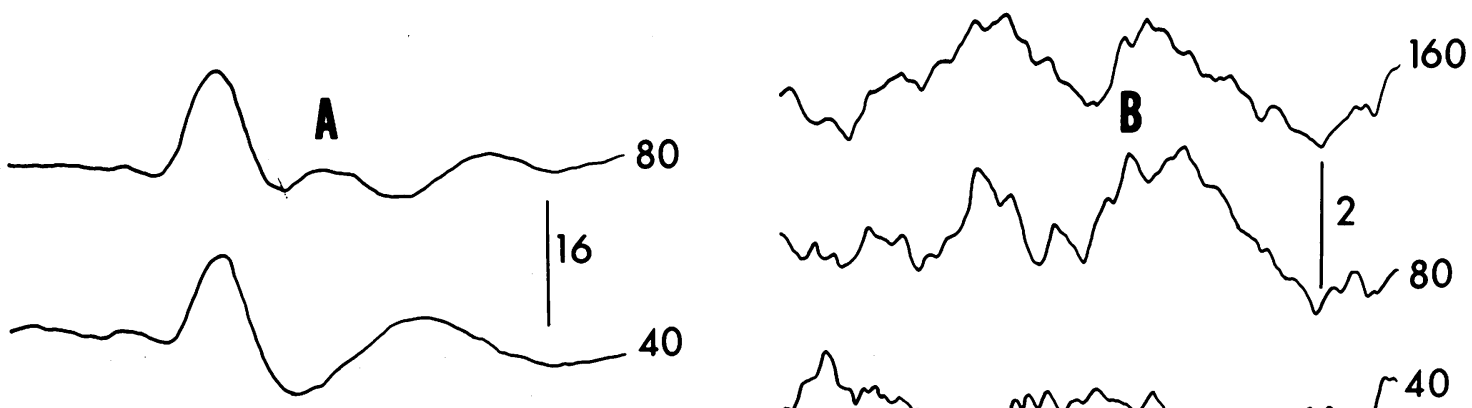

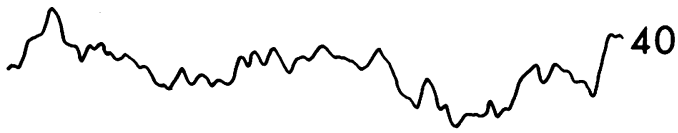
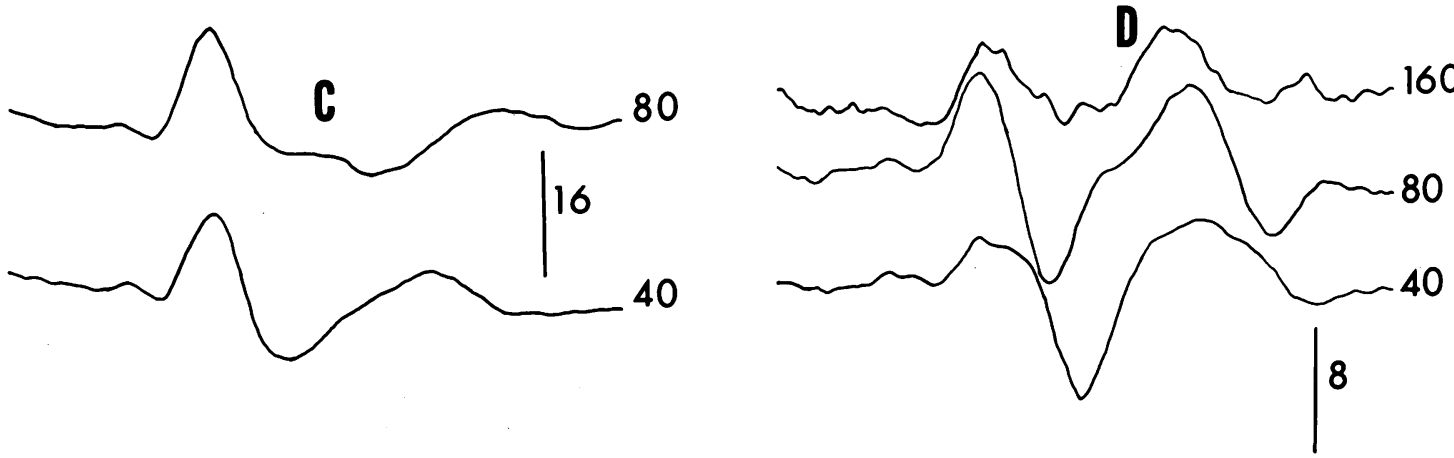

Fig. 1 Checkerboard pattern reversal VEPs before (A, B) and after (C, D) treatment for subject 164. A and $\mathrm{C}=$ nonamblyopic eye. $\mathrm{B}$ and $\mathrm{D}=$ amblyopic eye. Stimuli: black and white high contrast checks. Check size indicated in minutes of arc to the right of each trace. Reversal rate $1.88 \mathrm{~Hz}$. Field size 12 arc degrees. Each trace is the average of 256 contrast reversals. Electrodes: plus $=\mathrm{Oz}$ (10-20 International Electrode Placement System), minus $=C z$, ground $=P z$. Calibration: vertical line near each cluster of traces represents indicated number of microvolts. Each trace shows $300 \mathrm{~ms}$ following reversal of checkboard contrast. Recording bandpass 1 to $100 \mathrm{~Hz}$.

Snellen acuity. And subject 33 maintained her visual acuity at $20 / 60$. Ocular examination, including a dilated, careful fundus examination, revealed no abnormality of the anterior segment, lens, or fundus in any subject.

\section{Discussion}

The most dramatic effect of prolonged viewing of high luminance, high contrast gratings occurred in 2 strabismic amblyopes with central fixation (subjects 164 and 194). In these 2 subjects the amplitudes of the VEPs owing to stimulation of the amblyopic eye were substantially increased immediately after treatment, and these increases persisted for at least 3 weeks following treatment. The other 3 subjects were eccentric fixators. No significant change in VEP amplitude was measured for them. However, they had much larger VEPs owing to stimulation of the amblyopic eye, compared with that of the fellow nonamblyopic eye, to begin with than did the other 2 centrally fixing amblyopic subjects. Eccentric fixators usually have larger VEPs than do centrally fixing amblyopes with comparable visual acuity (Srebro, to be published), and this suggests that the neural input to the visual cortex is more attenuated in centrally fixing amblyopes than it is in eccentrically fixing amblyopes. Then it is plausible that the effect of the treatment on the amblyopic visual systems of the 2 centrally fixing amblyopes was to increase the neural input from the amblyopic eye to the visual cortex.

Single optotype Landolt-C acuity was improved in 4 of the 5 subjects studied. As Table 1 shows, Landolt-C acuity was better than line Snellen acuity in every case. This is in part owing to the crowding phenomenon well known to occur in amblyopia and in part owing to the choice of a $50 \%$ correct response 
level as a threshold criterion. The purpose of using the computer controlled video display technique for this measurement was to avoid any bias that the experimenter might introduce into the measurement. Some of the improvement in Landolt-C acuity may represent a practice effect. Only one subject (33) experienced an improvement in line Snellen acuity.

It is difficult to evaluate the subjective reports of the subjects, but the photopsias reported by 3 subjects were of concern in that they might have represented retinal damage. However, as discussed in the 'Methods' section, the radiation exposures were well within established safe limits for prolonged exposure, and no evidence of retinal damage was detected on careful fundus examination. Moreover, the photopsias were not confined to the retinal area stimulated.

The subjects chosen for this study were selected only on the basis of age ( 25 or older) and poor visual acuity (20/200 or worse). The choice of grating stimuli was suggested by previous studies,,$^{10}$ although no clear benefit is known to derive from viewing such gratings at ordinary luminance levels. " The study reported here is preliminary, and I make no general claim of efficacy. The treatment plan was arbitrary, and no controls were included. Nevertheless, I believe that the results are of sufficient interest to merit some attention.

\section{Referençes}

1 Rose A. Vision human and electronic. New York: Plenum Press, 1974: 1-27.

2 von Noorden GK, Burian HM. Visual acuity in normal and amblyopic patients under reduced illumination. I. Behavior of visual acuity with and without neutral density filter. Arch Ophthalmol 1959; 61: 533-5.

3 von Noorden GK, Burian HM. Visual acuity in normal and amblyopic patients under reduced illumination. II. The visual acuity at various levels of illumination. Arch Ophthalmol 1959; 62: 396-9.

4 Lawwill T, Burian HM. Luminance, contrast function and visual acuity in functional amblyopia. Am J Ophthalmol 1966; 62: 511-20.

5 Hess RF, Howell ER. The luminance-dependent nature of the visual abnormality in strabismic amblyopia. Vision Res 1978; 18: 931-6.

6 Hess RF, Campbell FW, Zimmern R. Differences in the neural basis of human amblyopias: The effect of mean luminance. Vision Res 1980; 20: 295-305.

7 Hess RF, Bradley A, Piotrowski L. Contrast-coding in amblyopia. I. Differences in the neural basis of human amblyopia. Proc $R$ Soc Lond (Biol 1983; 217: 309-30.

8 American national standards for the safe use of lasers (ANSI Z136.1), New York: American National Standards Institute, 1976.

9 Slincy DH. Laser safety. In: Hillenkamp F, Pratesi R, Sacchi $\mathrm{CA}$, eds. Past and present problem areas in lasers in biology and medicine. New York: Plenum Press, 1980: 421-42.

10 Campbell FW, Hess RF, Watson PG, Banks RV. Preliminary results of a physiologically based treatment of amblyopia. $\mathrm{Br} J$ Ophthalmol 1978; 62: 748-55.

11 Tytla ME, Labow-Daily LS. Evaluation of the CAM treatment for amblyopia: a controlled study. Invest Ophthalmol Visual Sci 1981; 20: 400-6. 